\title{
COVID-19 surveillance in the Flemish school system: development of systematic data collection within the Public Health School System and descriptive analysis of cases reported between October 2020 and June 2021
}

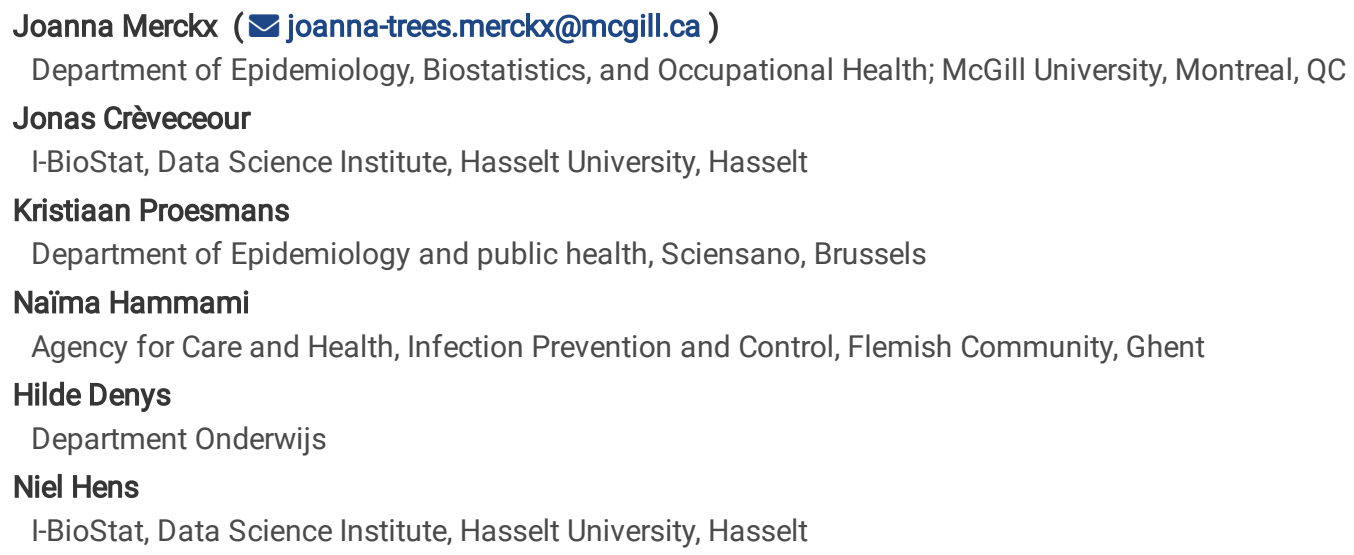

\section{Research Article}

Keywords: surveillance, schools, SARS-COV-2, children, cases, epidemiology, testing

Posted Date: January 5th, 2022

DOI: https://doi.org/10.21203/rs.3.rs-1192357/v1

License: (c) (i) This work is licensed under a Creative Commons Attribution 4.0 International License. Read Full License 


\section{Abstract \\ Background}

The age specific distribution of SARS-CoV-2 cases in schools is not well described. The numbers recorded reflect the intensity of community transmission while being shaped by biases from age-dependent testing regimes and effective age-specific interventions. A case-surveillance system was introduced within the Flemish school and health-prevention network during the 2020-2021 school year. We present epidemiological data of in-school reported cases in pre-, primary and secondary schools based on the surveillance system, in conjunction with test data and community cases from October 2020 to June 2021.

\section{Methods}

We describe the development of the surveillance system and provide the number of reported cases and standardized rates per grade over time. We calculate absolute and relative differences between incidence cases by grade of primary (grades 1-6) and secondary-school (grades 7-12) and compare these to grades 7-8, relating them to non-pharmaceutical infection prevention interventions. Cumulative population incidences (IP) stratified by age, province and social-economic status (SES) of the school population are presented with their $95 \%$ confidence intervals (CI).

\section{Results}

A total of 59,996 COVID-19 cases were reported in the school surveillance system, with the highest population adjusted IP in grade 11-12 of 7.39\% $(95 \% \mathrm{Cl} 7.24-7.53)$ and ranging from $2.23-6.25 \%$ from pre-school through grade 10 . Age-specific reduction in in-person teaching and introduction of masks, are temporally associated with decreases in incident cases by grades. Lower pupil SES is associated with increased cumulative cases (excess 2,739/100,000 pupils compared to highest SES tertile). Community testing volumes varied more for children compared to adults, with overall higher child test-positivity. Holidays influence capturing of cases by the system, however efficiency increased to above $75 \%$ after further automation and integration in existing structures.

\section{Conclusion}

Integration of case surveillance within an electronic school health system is feasible, provides data to follow up the epidemic evolution in schoolchildren and should be part of public health surveillance and pandemic preparedness. The relationship towards community transmission needs careful evaluation because of age-different testing regimens. In the Flemish region, case incidence within schools follows an age gradient that is mitigated through grade specific interventions, while differences by SES remain.

\section{Introduction}

In-person learning in primary and secondary schools is at the center of the educational system in countries all over the world, and is broadly considered the optimal environment for intellectual, personal and social development of children and teenagers (1). Prolonged duration of contact between large numbers of school children and teachers, provide, however, the potential for the spread of infectious diseases by airborne, droplet and contact transmission $(2,3)$. SARS-CoV-2 infection and transmission in the school environment have been under large scrutiny since the start of the pandemic. The lack of data or problematic selective data collection (4), e.g. availability of test data of symptomatic individuals only, and fast changing interventions, prohibited developing timely and clear insights in the specifics of COVID-19 in the pediatric population (5), and more in particular, of the transmission dynamics in school-aged children participating in in-person education. Systematic surveillance of cases specifically in the school setting can nonetheless be used to quantify changes in transmission dynamics, by age and time (6).

The COVID-19 pandemic is a public health emergency affecting individuals of different ages differently. Pediatric cases are in general mild and not captured through hospitalization or health care visit data $(7,8)$. Reporting of admitted children only gives a selected and biased estimate of infection rates in the pediatric population. Infection and transmission, including outbreaks at schools involving both pupils and staff, has been documented $(9,10)$. The role of transmission in school and the interaction with community and household transmission requires scrutinous study by applying quantitative epidemiological tools and collecting data within the school environment, while linking with community data (11). A solid surveillance system that can be set up and used during epidemics can be a resourceful tool to measure the impact of interventions and to timely inform decision making.

In Belgium, schools were gradually and partly re-opened in the spring of 2020 as part of the exit strategy following the first wave and corresponding lockdown. All primary and secondary schools, both from the Flemish and French language school system, restarted full-time inperson education on September 1st, 2020. Flemish schools are under the responsibility of the Ministry of Education of the Flemish region and all public and private schools that are approved and financed or subsidised by the Flemish government, are connected to the school public health 
system directly, organized through Student Guidance Centres (CLB's = Centra voor Leerlingenbegeleiding). Within this structure and with the help of the national public health agency, Sciensano, and the regional public health agency, "Vlaams Agentschap Zorg en Gezondheid" (VAZG), a COVID-19 school surveillance system was set up in September 2020 with occasional adjustments during the school year. Parallel, in the French region, a similar system was developed with separate data collection and supervision, though final aggregation of the data by Sciensano.

The aim of this manuscript is to (i) describe the development of a surveillance and testing-and-tracing system for COVID-19 cases and potential school transmission in Flemish pre-, primary and secondary-schools and to (ii) describe the frequency and epidemic curve of SARS-CoV-2 confirmed school cases by age group from October 2020 to June 2021, in conjunction with non-pharmaceutical interventions (NPI) implemented to control transmission in schools, the community background incidence and national age-specific test data, using data from the surveillance school database.

\section{Methods \\ Study design and study population}

This is a prospective cross-sectional surveillance study of SARS-CoV-2 confirmed and reported cases in all children attending public and governmental-supported pre-, primary and secondary schools of the Flemish Community in Belgium, from October 5th, 2020, until June 27th, 2021. Special education schools and their pupils are not included in the study.

The Flemish school system is organized in three educational publicly funded networks and counts 2.454 pre- and primary schools and 948 secondary schools (12), with a total of 1,106,194 registered pupils in February 2020 (13). The school health network consists of 58 independent Student Guidance Centers (CLB's), including medical doctors and nurses responsible for preventive health care, and is under the responsibility of the Flemish government. Data on confirmed and reported SARS-CoV-2 cases among school personnel was not consistently available during the surveillance period and is therefore not included in this study.

\section{Development of the surveillance network}

The surveillance system was set up at the start of the new school year on September 1st, 2020, within the Flemish government-aided education school network, nested within the school health network (CLB) and guided by VAZG and Sciensano. All children who tested positive with a Polymerase Chain Reaction (PCR) test on an upper respiratory tract sample and who physically attended the school were entered in the surveillance system as individual laboratory confirmed cases. It is the responsibility of the school to report confirmed cases to their CLB responsible who then performs an investigation of the case through contact with the school, pupil and his/her parent or guardian. Investigation entails contact and contact-risk assessment in the school environment and, if necessary, prescription of testing. Infection prevention and control guidelines were prepared by the Ministry of Education and guidelines for testing, contact tracing and quarantine were available for all schools in Flanders and in coordination with VAZG. When a cluster is detected in a school, i.e., 2 or more potentially related cases within a period of 14 days, the CLB responsible contacts the regional public health unit VAZG, for registration of the outbreak and if necessary, further in-depth analysis, screening and contact-tracing embedded within the national contact tracing network. CLB clinicians and personnel are bound to patient confidentiality and to securely save the information. Data was initially collected using spreadsheets completed by the CLB's and collected by the Ministry of Education and Sciensano. As of October 5th 2020, surveillance data are entered, tracked and can be shared through the secured school health automated platform LARS (Leerling Activiteiten en Registratie Systeem) which secures availability of pupil demographic data. As per November 22nd 2020 this was the only data registration pathway. Data is extracted and compiled to anonymized datafiles per CLB and transferred to i) the Ministry of Education on a 2-weekly basis for policy guidance at the level of the ministry and to ii) the regional public health services and Sciensano. Sciensano publicly reports the data together with school data from the French language school network (Brussels and Wallonia) in the weekly epidemiologic bulletin section 'Situation of COVID-19 in Children' (14) and in the weekly risk assessment report of Sciensano (15).

From January 18th 2021, a daily automated data flow was set up between i) the SARS-CoV-2 positive test results available in the communitytesting driven data platform of VAZG and ii) the school system, LARS, allowing more time-efficient case detection and management by the CLB's. The data of the contact tracing in LARS are transferred back to the data platform at VAZG to inform the regional public health unit about the situation in schools. A complete list of the collected variables used in the LARS database and used for the data analysis are: name of child, date of registration of a positive case, child's class and school level, reason for SARS-CoV-2 testing, probable place of infection, secondary cases linked to the index case, number of children and number of personnel in quarantine after registration of the case.

\section{Non-pharmaceutical infection prevention and control interventions (NPIs) with implications for schools}

When schools were opened on September 1st 2020 with in-person education for all pupils of all grades, masks were introduced from grade 7 and up to be worn in class and outside class, when keeping a distance of at least $1.5 \mathrm{~m}$ was found impossible; as for all adult personnel in all school institutions, except for in class contact with pre-school children. Physical distancing between adults was encouraged, however not enforced

Page $3 / 11$ 
between pupils. Hand hygiene was promoted. Class bubbles were not kept separate in most elementary schools (16) and no changes in class size were introduced. The pre-scheduled one-week Fall break started on 31st of October 2020 for all pupils, with prolongation until November 15 th 2020. Pre-schools and primary schools were fully re-opened on November 16th, while part-time in person education and part time home education for all pupils from grade 9 and up was initiated, resulting in an overall $50 \%$ attendance (either with or without reduction of class sizes which was decided on school level) and non-mixing of class bubbles. The winter break remained unchanged (week of December 21 st 2020 until January 4 th 2021). The week of March 22nd 2021, mask wearing was introduced in class for pupils in the 5th and 6th grade. The Easter Holidays were advanced with one week, defined as suspension of all education institutions between March 29th and April 2nd, except continuation of in-person examinations, resulting in a total duration of the April vacation of three weeks for elementary schools. Key school-related NPIs are represented in Figure 1. Additional details can be found in the Supplement.

Diagnostic testing for confirmation of acute SARS-CoV-2 infection during the 2020-2021 school year was mainly performed using PCR tests (only limited use of antigen tests in the period under investigation) and is captured in the national surveillance system of Sciensano (17, 18). National testing strategies changed between October 21th and November 23rd 2020 because of test capacity issues in conjunction with a large surge in community cases. During this period only individuals with symptoms suspected for COVID-19 disease were tested thereafter testing of all potentially infected cases and of those with high-risk contact (HRC) was re-introduced. As of January 2021, large testing campaigns were initiated in schools, mainly driven by the increase of the alpha variant in the community. Testing frequency was also intensified for HRC after January 25 th 2021, with two recommended test moments after identification of the contact (19). Contact tracing was performed in schools using the described surveillance system, with differential measurements of quarantine for high versus low-risk contacts and age-dependent (e.g. less than versus more than 6 year old) and NPI-dependent (e.g. mask versus no mask on exposure) assignment of risks and consequential testing.

\section{Data sources}

For the analysis, anonymized data from the surveillance network were transferred on a 2-weekly basis to the study team, starting with the first data collection using the automated platform LARS (Week October 5th 2020). In addition, we used age-stratified community reported test data from the National COVID-19 laboratory network surveillance as centralized by Sciensano. This data is available in real-time for the regional public health services, including PCR and antigen tests performed in Flanders, by age, date of sampling and test result (18).

Population numbers by age and municipality were extracted from Statbel (20) for the denominators. Pupil number data by school level and school are based on 2019-2020 academic year data (13). An overview of NPIs in place at the school and community level, by time of implementation, was provided by the Department of Education. Socioeconomic pupil indicators by school, publicly available for financial and resource allocation in the Flemish school system (21), were combined to a summary socioeconomic status (SES) variable, including maternal education, language spoken at home, pupil subsidy for education and neighborhood's delay in schooling.

This study provides aggregate anonymized data. No ethical approval was needed for the analysis and the data were provided by the Ministry of Education and Sciensano to the study team in accordance with a data agreement for the age-stratified community test data.

\section{Data analysis}

We provide a descriptive analysis. Cases captured in the surveillance system are presented in absolute numbers and as weekly (Monday to Sunday) incidence proportions per 100,000 population by school grade and by time. Absolute and relative differences in age-stratified case incidences between ages are presented over time in figures. Crude absolute cumulative incidence numbers by grade, province and SES level are presented in tables with their $95 \%$ confidence intervals (CI). Expected and observed number of cases are compared by SES using binomial testing. A supplementary analysis investigates (i) case increments over time versus tests in the community in children and in adults and (ii) adult versus child test positive rates using plots. Statistical analysis was performed in R version 4.0.2 (R Foundation for Statistical Computing, Vienna, Austria, 2020) and STATA 13 (Statcorp. College Station, TX).

\section{Role of funding}

The surveillance system is under the responsibilities of the Ministries of Education and Health and did not receive additional or specific funding. The investigators involved in the study did not receive separate funding for the analysis. All investigators had access to the anonymized and secured surveillance data.

\section{Results}

\section{Cumulative cases:}

Between October 5th 2020 and June 27th 2021 a total of 59,996 cumulative acute pupil COVID-19 cases were reported in the Flemish school surveillance system (Table 1). Pupils from pre-school and enrolled in grade 1-2 had the lowest population adjusted cumulative incidence, $2.23 \%$ (95\% $\mathrm{Cl} 2.17-2.29)$ and $5.23 \%(95 \% \mathrm{Cl} 5.11-5.34)$, respectively. Cumulative incidences in pupils from grade $3-4$ and up through grade $9-10$ were similar, ranging from $6.22-6.94 \%$. Grade $11-12$ pupils had the highest cumulative incidence of reported cases of $7.39 \%$ (95\% $\mathrm{Cl} 7.24-7.53$ ). 
Provincial differences apply, with incidences ranging from 3.62\% (95\% Cl 3.54-3.71) in Flemish-Brabant to $6.85 \%$ (95\% Cl 6.62-7.08) in the Brussels Capital region. Incremental differences are seen in cumulative incidence of cases by pupil SES score, with significantly fewer cases in schools in the highest SES tertile compared to the middle and lowest SES tertile. There is an absolute excess of 2,739 cases per 100,000 pupils in pupils attending schools in the lowest SES tertile compared to the highest tertile (Table 1).

Table 1

Cumulative number and cumulative percentage of COVID-19 reported cases in the surveillance system

\begin{tabular}{|c|c|c|c|}
\hline & $\begin{array}{l}\text { Cumulative number of reported SARS-CoV-2 } \\
\text { cases }\end{array}$ & Population & $\begin{array}{l}\text { Cumulative percentage reported ( } 95 \% \\
\mathrm{Cl})\end{array}$ \\
\hline School grades Total & 59,996 & & \\
\hline pre-school & 5,825 & 261,131 & $2.23(2.17-2.29)$ \\
\hline grade $1-2$ & 7,583 & 145,074 & $5.23(5.11-5.34)$ \\
\hline grade $3-4$ & 9,419 & 142,514 & $6.61(6.48-6.74)$ \\
\hline grade $5-6$ & 9,527 & 137,311 & $6.94(6.80-7.07)$ \\
\hline grade $7-8$ & 9,461 & 152,076 & $6.22(6.10-6.34)$ \\
\hline grade $9-10$ & 8,883 & 142,087 & 6.25 (6.13-6.38) \\
\hline grade 11-12 & 9,298 & 125,879 & 7.39 (7.24-7.53) \\
\hline Provinces Total & 59,996 & & \\
\hline Antwerpen & 16,574 & 312,393 & $5.31(5.23-5.38)$ \\
\hline $\begin{array}{l}\text { Brussels Hoofdstedelijk } \\
\text { Gewest }\end{array}$ & 3,292 & 48,077 & 6.85 (6.62-7.08) \\
\hline Limburg & 7,985 & 138,495 & 5.77 (5.64-5.89) \\
\hline Oost-Vlaanderen & 15,726 & 250,477 & $6.28(6.18-6.37)$ \\
\hline Vlaams-Brabant & 6,291 & 173,659 & 3.62 (3.54-3.71) \\
\hline West-Vlaanderen & 10,128 & 182,971 & $5.54(5.43-5.64)$ \\
\hline $\begin{array}{l}\text { Socioeconomic } \\
\text { Status school population }\end{array}$ & \multicolumn{2}{|c|}{ Status school population Total } & \\
\hline SES high & 14,995 & 365,071 & $4.11(4.04-4.17)$ \\
\hline SES mid & 19,572 & 376,020 & $5.21(5.13-5.28)$ \\
\hline SES low & 25,006 & 364,981 & 6.85 (6.77-6.93) \\
\hline
\end{tabular}

Surveillance system epidemic curve of reported cases by age

The epidemic curve of grade specific reported SARS-CoV-2 cases per week per 100,000 children is presented in Figure 1. School holiday periods and changes in NPIs are marked. Figure 2 shows the absolute difference in cases per week per 100,000 by grades, taking grade 7-8 as the reference (relative ratio by grades presented in Supplement Figure 2). The positive association between age and number of cases that is seen at the start of the reporting resolves temporally after the initiation of $50 \%$ in-person education in grades 9 and up. The largest difference in weekly cases per 100,000 pupils was 295 extra cases in pupils of grade 11-12 during the week of October 26th. The distribution of the proportion of reported cases by grade and time is presented in Figure 3 and shows that with the evolution of the epidemic and with the NPIs and testing regimens in place, the age differences decrease and shift from grade 11-12 to grade 5-6. Grade 5-6 have the highest case burden after midNovember 2020, increasing to 256 more cases per week per 100,000 pupils mid-March 2021 compared to grade 7-8 (Figure 2). This excess compared to other age groups dissolves temporally after the introduction of masks in grade 5-6.

Influence of community testing and community cases 
Figure 4 visualizes weekly incidence community test-positive cases per 100,000 inhabitants aged 20 to 79 against the incidence cases in children captured in the surveillance network. Figure 5 shows the evolution in the number of tests performed in the community and positive tests in children 6 to 11 yo and 12 to17yo over time, with larger age dependent changes in testing rates compared to positivity rates. Further investigation of testing in relation to confirmed cases in children (Fig. 6A) and adults (Fig. 6B) shows a similar evolution over time, although with more variability in the number of tests per 100,000 children compared to adults. Overall test positivity rates in children are higher compared to those in adults (Supplement Figure 3).

\section{Reporting effectiveness}

Holiday periods and changing test strategies are visually (Figure $1 \& 2$ ) associated with shifts in case reporting. Cases captured in the surveillance system are equally dependent on holiday periods when compared with the nationally reported number of positive tests (Figure 7 ) with $60 \%$ reporting rate outside holidays and with only $1 / 4$ of cases being reported during the first holiday periods of the academic year. Almost absolute reporting in the surveillance system is achieved after automated linkage and streamlined reporting of cases between the public health laboratory surveillance and the school health network, by exporting the laboratory confirmed cases directly into LARS after January 18th 2021. Some potential lag-times in reporting however remain, but those have been proven to be limited, due to the almost real-time reporting of most laboratories to the central COVID-19 testing database.

\section{Discussion}

We describe the COVID-19 epidemic evolution in a large Belgian region where schools have been reopened and remained open almost the entire school year 2020-2021, using data from a newly developed school-network based surveillance program. We show that it is feasible to set up a surveillance network within the present structures of the school and school health network when a digital platform is available. We provide a descriptive analysis of the Flemish region school COVID-19 surveillance program, with presentation of age-specific data.

Age is one of the most important predictors of morbidity and mortality by COVID-19 (22,23.24). The presence and importance of age-dependent susceptibility and transmission remain unclear, even more so with the change in dynamics with the spread of SARS-CoV-2 variants of concern and with vaccination in the adult population (25). In Flanders, SARS-CoV-2 vaccination was introduced during the last trimester of the reporting period of this study in the Flemish adult population and not suspected to have yet reached a coverage to see an impact on the transmission dynamics in school-aged children. The positive association between age and number of cases at the start of the school year in this study appears, at least temporally, to have disappeared, through a combination of age-specific NPIs and NPI and age-dependent testing rules, with a decrease in cases in grade 11-12 after the shift to $50 \%$ education and later decrease in cases in grade 5-6 after the introduction of face masks. We find no statistically significant difference between cumulative cases from grade 5-6 through grade 9-10 after March 2020.

We show that testing has been very heterogeneous over time during the epidemic in the pediatric population and differential to the adult population. Testing regimens influence the tests per population performed more in the pediatric than the adult population (26). Changing testing strategies, linked to contact risk stratification, in addition to decreased incentives to get testing for children while not at school, i.e. during school vacations or distance learning, provide missed opportunities for a more complete capturing and continuous follow up of the epidemic evolution in school aged children. Rules for assignment of high-risk versus low-risk contacts have implications for further testing, evaluation and quarantine. They directly affect case investigation and detection in the affected pupils. Adherence to these procedures therefore further affects and feeds the case finding and surveillance data without the possibility to have the ultimate complete data set and numerator of the truly infected. Our data thus far do not allow an unbiased estimate of the impact of testing regimens on the age-specific proportion of detected cases versus those undiagnosed (27), nor can we quantify, in this sample, the impact of testing as a sole NPI. However, without the timely HRC identification, quarantine, school-initiated testing, diagnosis and isolation of positive cases, which is made possible through the integration of the school surveillance system in the public health framework, likely more cases were to have remained undiagnosed allowing continued spread of the virus. The high-quality tracing activities of the CBL staff, with their ability to prescribe additional testing, contributed substantially to the efficiency of the general contact tracing, in addition to feeding the surveillance system. We cannot, however, completely describe the administrative hurdles experienced in the set-up and maintenance of the surveillance system by the responsible agencies. The burden on the CLB clinical and general staff corps has been high. It needs to be recognised that time and energy investment in surveillance systems oriented on one infectious disease take away necessary time for other core activities oriented towards supporting the broader health in the school aged population.

A stark finding is that pupils from schools with the lowest SES carried a quantified and important higher burden of COVID-19 over the 2020-2021 school year in our study. Flanders has no large network of private schools and the NPIs equally apply in all schools, however, the differences in cumulative incidence show how social characteristics of pupils as part of social arrangements in society also in the Flemish region differentially shape infectious disease dynamics and result in unequal disease burden. Data on disparities in the burden of COVID-19 in the general population have been published $(28,29,30)$. Schools and pupils mirror our society and investigating the risk factors for infection and disease should include the assessment of the role of social determinants of health $(29,31)$, independent and specifically for the pediatric population $(32,33)$. The 
pandemic clearly illustrates how this infectious disease pandemic is equally a social pandemic and implies that we need to provide additional support to the most vulnerable children and families.

The found differences in cumulative incidence by province reflect the heterogeneous provincial distribution of community cases. Even in the densely populated and well-connected region of Flanders, SARS-CoV-2 infection rates show a local distribution (34), dependent on heterogeneous mixing patterns and subject to different policies $(35,36)$. Research shows that transmission in schools depends on the level of community transmission $(37,38)$. School cases show a high correlation with the evolution of community cases in the general population in our study.

There are multiple lessons learned from the implementation of the surveillance system and the analysis of its collected data. To improve data quality and to minimize the missingness of important variables, the introduction and inclusion of surveillance within an existing digital platform has proven to be crucial given collection of data by use of excel documents is insufficient, mainly to capture meta-data correctly. Variable definition can lead to unintended loss of information, for example, while the clinicians from the CLB's gathered data on the presence of symptoms in tested individuals, this was not reflected in the data collection where only a single reason for testing (symptoms or HRC) could be entered. Hence, the reason of testing could not directly be used to assess the impact symptoms play in this pediatric population on testing and case detection. Nor was it possible to, with minimal risk for misclassification, calculate the secondary attack rate (SAR) in schools, an estimate of interest (397). Further already implemented adaptations, including the use of linked laboratory surveillance system collected data, will allow analyses of outbreak size, SAR and reporting of proportion of symptomatic cases for following surveillance periods.

The school environment of course does not only contain school children. The close interaction with the adult teaching and support staff has been the main concern for keeping the schools open, once the relatively low direct impact on morbidity $(40,41)$ and extremely low mortality $(42)$ in the pediatric population became evident. The joint collection of cases in staff and pupils undoubtedly would add beneficial data, however this was shown complex and mainly burdened by administrative and other hurdles in this sample.

Availability of surveillance data serves multiple purposes (43). The surveillance data described in this study are bi-weekly presented to the Ministry of Education and also included in the Sciensano weekly updates $(14,15)$. Surveillance programs can detect and follow the evolution of registered cases in the school environment and provide baseline and follow-up data that can be compared to community surveillance data.

Suggestions to improve the data collection tool are the following: Addition of data of school absenteeism $(44,45)$, inclusion of total number of children tested (including data on test negatives), separate collection of the variable capturing the presence or absence of symptoms and the opportunity to report additional instituted interventions during a class or school outbreak for later evaluation of its impact on the size and time to containment of the outbreak. The surveillance network can be used for follow-up and to perform impact evaluations (46) of changes in school level interventions, like e.g. shifts in in-person education, changes in mask mandates, test modalities (antigen versus PCR) used for outbreak investigations, and others. With the availability of high-quality data, predictive models can be developed as alarm systems informing on the epidemic evolution and including calculation of the (changes in) SAR. Estimation of the attributable effect of interventions on the change of cases can in addition provide evidence relevant for policy decisions. In the future one can also foresee that information on vaccination coverage and more details on the circulating SARS-CoV-2 variants, are valuable for further study and inclusion in the analyses.

\section{Conclusion}

Installation of a surveillance system for a new infectious disease within a school health system is feasible and provides useful data on the evolution of the pandemic in the school environment. A school surveillance system for recurrent and new infectious diseases, which is automated and embedded in a structural manner within the public health system will improve epidemic response and can more swiftly provide epidemiological and scientific insights.

In the Flemish region associations between age and incidence case rates dissolved, hypothetically mitigated through age-specific school-level interventions, though potentially residually biased by age and intervention dependent changes in testing strategies. Differences in incidence by SES, however, remained.

\section{Abbreviations}

CLB: Centrum voor Leerlingenbegeleiding; Student Guidance Centers

$\mathrm{Cl}$ : confidence interval

COVID-19: Coronavirus disease of 2019

HRC: high-risk contact

IP: incidence proportion, cumulative population incidences, incidence rates 
LARS: Leerling Activiteiten en Registratie Systeem

NPIs: Non-pharmaceutical infection prevention and control interventions

PCR: polymerase chain reaction

SAR: secondary attack rate

SARS-CoV-2 : severe acute respiratory syndrome coronavirus 2

SES: socioeconomic status

VAZG: Vlaams Agentschap Zorg en Gezondheid

\section{Declarations}

Acknowledgements: We are thankful for the collaboration with the Department Onderwijs and grateful to all the colleagues at the CLBs for their efforts in the collection of the data and their work during the 2020-2021 academic year. We thank Sciensano for providing the age-specific testing data and for enabling the integration of the multiple data sources. We thank more specifically Laura Cornelissen and Sofieke Klamer, Sciensano, for their aid and detailed referencing of the public health data. $\mathrm{NH}$ acknowledges support from the European Research Council (ERC) under the European Union's Horizon 2020 research and innovation program (Grant Agreement 682540 TransMID and EpiPose: Epidemic intelligence to Minimize COVID-19's Public Health, Societal and Economical Impact).

Ethical approval: This study provides aggregate anonymized data. Ethical approval was not considered for this research and the data were provided by the Ministry of Education and Sciensano following, for the latter, a data request by the study team.

Consent for publication: No identifiable data is included in the manuscript.

Availability of data and materials: The datasets used and/or analysed during the current study are available at the aggregate level from the corresponding author on reasonable request.

Competing interests: The authors declare no competing interests.

Funding: The authors did not receive funding for this project. The surveillance system is under the responsibilities of the Ministry of Education and Health and did not receive additional or specific funding. The investigators involved in the study did not receive separate funding for the analysis. All investigators had access to the anonymized and secured data.

Authors' contributions: JM, JC and NH made substantial contributions to the conception and design of the work. HD did data collection and transfer. JM and JC did the data acquisition. JM, JC and $\mathrm{NH}$ were involved in the data analysis, with JC providing the data output and producing the graphs. JM, JC and $\mathrm{NH}$ did the interpretation of the data. JM made the first draft of the manuscript; JM, JC and NH did revisions to the manuscript. $\mathrm{NHa}, \mathrm{KP}$ and $\mathrm{HD}$ reviewed the article and made comments for improvement of the quality of the manuscript. All authors have read and approved the final version to be published.

\section{References}

1. Darling-Hammond, L., Flook, L., Cook-Harvey, C., Barron, B., \& Osher, D. Implications for educational practice of the science of learning and development. Applied Developmental Science. 2020;24(2): 97-140.

2. Robinson J. Infectious diseases in schools and child care facilities. Pediatrics in review. 2001;22(2):39-46.

3. Liu QH, Ajelli M, Aleta A, Merler S, Moreno Y, Vespignani A. Measurability of the epidemic reproduction number in data-driven contact networks. Proceedings of the National Academy of Sciences. 2018;115(50):12680-5.

4. Pagel C, Yates CA. Tackling the pandemic with (biased) data. Science. 2021;22;374(6566):403-4.

5. Gaythorpe KA, Bhatia S, Mangal T, Unwin HJ, Imai N, Cuomo-Dannenburg G, Walters CE, Jauneikaite E, Bayley H, Kont MD, Mousa A. Children's role in the COVID-19 pandemic: a systematic review of early surveillance data on susceptibility, severity, and transmissibility. Scientific reports. 2021 Jul 6;11(1):1-4.

6. Goldstein E, Pitzer VE, O'Hagan JJ, Lipsitch M. Temporally varying relative risks for infectious diseases: implications for infectious disease control. Epidemiology. 2017;28(1):136.

7. Kushner LE, Schroeder AR, Kim J, Mathew R. "For COVID” or “With COVID”: Classification of SARS-CoV-2 Hospitalizations in Children. Hospital Pediatrics. 2021; doi: 10.1542/hpeds.2021-006001 
8. Bourgeois FT, Gutiérrez-Sacristán A, Keller MS, Liu M, Hong C, Bonzel CL, et al. International Analysis of Electronic Health Records of Children and Youth Hospitalized With COVID-19 Infection in 6 Countries. JAMA network open. 2021;4(6):e2112596-

9. Stein-Zamir C, Abramson N, Shoob H, Libal E, Bitan M, Cardash T, et al. A large COVID-19 outbreak in a high school 10 days after schools' reopening, Israel, May 2020. Eurosurveillance. 2020;25(29):2001352.

10. Lam-Hine T, McCurdy S.A, Santora L, Duncan L, Corbett-Detig R, Kapusinszky b, et al.Outbreak Associated with SARS-CoV-2 B. 1.617. 2 (Delta) Variant in an Elementary School-Marin County, California, May-June 2021. MMWR Morb Mortal Wkly Rep 2021;70:1214-1219

11. Lessler J, Grabowski MK, Grantz KH, Badillo-Goicoechea E, Metcalf CJ, Lupton-Smith C, et al. Household COVID-19 risk and in-person schooling. Science. 2021;372(6546):1092-7.

12. Statistisch jaarboek van het Vlaams onderwijs; Flemish Ministry of Education. https://onderwijs.vlaanderen.be/nl/statistisch-jaarboek-vanhet-vlaams-onderwijs-2019-2020 Accessed on March 6th 2021.

13. Dataloep: aan de slag met cijfers over onderwijs - Vlaams Ministerie van Onderwijs en Vorming (vlaanderen.be). Data numbers of pupils Flanders. http://dataloep-publiek.vlaanderen.be/QvAJAXZfc/notoolbar.htm?document=LP-

Publiek\%2FPubliek_Inschrijvingen_leerplicht.qvw\&host=PubliekQVS\%40cwv100163\&anonymous=true Accessed on February 6th 2021.

14. COVID-19 Wekelijks Epidemiologisch Bulletin. Sciensano. June 2021. Brussels. D/2020/14.440/46 available on https://covid19.sciensano.be/sites/default/files/Covid19/COVID-19_Weekly_report_FR.pdf Accessed on September 21th 2021.

15. Weekly risk Assessment Report of Sciensano available on https://covid-

19.sciensano.be/sites/default/files/Covid19/RAG_Derni\%C3\%A8re\%20mise\%20\%C3\%A0\%20jour\%20\%C3\%A9pid\%C3\%A9miologique_FR.pdf. Accessed September 21th 2021. Methodological protocol on https://covid-19.sciensano.be/sites/default/files/Covid19/COVID-

19_THEMATIC\%20REPORT_SCHOOLS_SURVEILLANCE.pdf Accessed on September 21th 2021.

16. Duysburgh E, Merckx J, Callies M, Kabouche I, Vermeulen M, Roelants M, et al. Prevalence and incidence of antibodies against SARS-CoV-2 in children and school staff measured between December 2020 and June 2021: an observational sero-prevalence prospective cohort study Findings of the first testing period Brussels, Belgium: Sciensano ; 2021. Report number: D/2021/14.440/10.

17. Sciensano epistat website. https://epistat.wiv-isp.be/Covid/ Accessed July 14th, 2021.

18. Meurisse M, Lajot A, Dupont Y, Lesenfants M, Klamer S, Rebolledo J, Lernout T, Leroy M, Capron A, Van Bussel J, Quoilin S. One year of laboratory-based COVID-19 surveillance system in Belgium: main indicators and performance of the laboratories (March 2020-21). Archives of Public Health. 2021 Dec;79(1):1-9

19. Braeye T, Cornelissen L, Catteau L, Haarhuis F, Proesmans K, De Ridder K, Djiena A, Mahieu R, De Leeuw F, Dreuw A, Hammami N. Vaccine effectiveness against infection and onwards transmission of COVID-19: Analysis of Belgian contact tracing data, January-June 2021. Vaccine. 2021:15;39:5456-60.

20. Statbel. Bevolking naar woonplaats, nationaliteit, burgerlijke staat, leeftijd en geslacht. (2019). https://statbel.fgov.be/nl/opendata/bevolking-naar-woonplaats-nationaliteit-burgerlijke-staat-leeftijd-en-geslacht-9 Accessed February 6th, 2021

21. Dataloep: aan de slag met cijfers over onderwijs - Vlaams Ministerie van Onderwijs en Vorming (vlaanderen.be). Data socio-economic pupil indicators by school. https://dataloep-publiek.vlaanderen.be/QvAJAXZfc/notoolbar.htm?document=LP-

Publiek\%2FPubliek_Leerlingenkenmerken.qvw\&host=PubliekQVS\%40cwv100163\&anonymous=true Accessed on February 6th 2021.

22. O'Driscoll M, Dos Santos GR, Wang L, Cummings DA, Azman AS, Paireau J, et al. Age-specific mortality and immunity patterns of SARS-CoV2. Nature. 2021;590(7844):140-5.

23. Piroth L, Cottenet J, Mariet AS, Bonniaud P, Blot M, Tubert-Bitter P, et al. Comparison of the characteristics, morbidity, and mortality of COVID19 and seasonal influenza: a nationwide, population-based retrospective cohort study. The Lancet Respiratory Medicine. 2021;9(3):251-9.

24. Mallapaty S. The coronavirus is most deadly if you are old and male. Nature. 2020 Sep 3;585(7823):16-7.

25. Head JR, Andrejko KL, Remais JV. Model-based assessment of SARS-CoV-2 Delta variant transmission dynamics within partially vaccinated K-12 school populations. medRxiv. 2021. doi.org/10.1101/2021.08.20.21262389

26. Holden TM, Richardson RA, Arevalo P, Duffus WA, Runge M, Whitney E, et al. Geographic and demographic heterogeneity of SARS-CoV-2 diagnostic testing in Illinois, USA, March to December 2020. BMC public health. 2021;21(1):1-3.

27. Viner RM, Ward JL, Hudson LD, Ashe M, Patel SV, Hargreaves D, et al. Systematic review of reviews of symptoms and signs of COVID-19 in children and adolescents. Archives of disease in childhood. 2021;106(8):802-7.

28. Rossen LM, Ahmad FB, Anderson RN, Branum AM, Du C, Krumholz HM, et al.. Disparities in Excess Mortality Associated with CoVID-19United States, 2020. Morbidity and Mortality Weekly Report. 2021;70(33):1114.

29. Mena GE, Martinez PP, Mahmud AS, Marquet PA, Buckee CO, Santillana M. Socioeconomic status determines COVID-19 incidence and related mortality in Santiago, Chile. Science. 2021;372(6545).

30. Nafilyan V, Islam N, Mathur R, Ayoubkhani D, Banerjee A, Glickman M, et al. Ethnic differences in COVID-19 mortality during the first two waves of the Coronavirus Pandemic: a nationwide cohort study of 29 million adults in England. European journal of epidemiology. 2021;36, 605617. 
31. Khalatbari-Soltani S, Cumming RC, Delpierre C, Kelly-Irving M. Importance of collecting data on socioeconomic determinants from the early stage of the COVID-19 outbreak onwards. J Epidemiol Community Health. 2020;74(8):620-3.

32. Lachman P. Where to make a difference: research and the social determinants in pediatrics and child health in the COVID-19 era. Pediatric research. 2021;89(2):259-62.

33. Modi N, Hanson M. Health of women and children is central to covid-19 recovery. BMJ. 2021;373.

34. Molenberghs G, Buyse M, Abrams S, Hens N, Beutels P, Faes C, et al. Infectious diseases epidemiology, quantitative methodology, and clinical research in the midst of the COVID-19 pandemic: Perspective from a European country. Contemporary Clinical Trials. 2020;99:106189.

35. Coletti P, Wambua J, Gimma A, Willem L, Vercruysse S, Vanhoutte B, et al. CoMix: comparing mixing patterns in the Belgian population during and after lockdown. Scientific reports. 2020;10(1):1-0.

36. Desson Z, Weller E, McMeekin P, Ammi M. An analysis of the policy responses to the COVID-19 pandemic in France, Belgium, and Canada. Health Policy and Technology. 2020;9(4):430-46.

37. Boey L, Roelants M, Merckx J, Hens N, Desombere I, Duysburgh E, et al. Age-dependent seroprevalence of SARS-CoV-2 antibodies in schoolaged children from areas with low and high community transmission. Eur J Pediatr. 2021;1-8.doi: 10.1007/s00431-021-04222-9.

38. Ismail SA, Saliba V, Bernal JL, Ramsay ME, Ladhani SN. SARS-CoV-2 infection and transmission in educational settings: a prospective, crosssectional analysis of infection clusters and outbreaks in England. The Lancet Infectious Diseases. 2021;21(3):344-53.

39. Merckx J, Labrecque JA, Kaufman JS. Transmission of SARS-CoV-2 by children. Deutsches Ärzteblatt International. 2020;117(33-34):553.

40. Payne AB, Gilani Z, Godfred-Cato S, Belay ED, Feldstein LR, Patel MM, et al. Incidence of Multisystem Inflammatory Syndrome in Children Among US Persons Infected With SARS-CoV-2. JAMA network open. 2021;4(6):e2116420-.

41. Molteni E, Sudre CH, Canas LS, Bhopal SS, Hughes RC, et al. Illness duration and symptom profile in symptomatic UK school-aged children tested for SARS-CoV-2. Lancet Child Adolesc Health. 2021. doi.org/10.1016/S2352-4642(21)00198-X

42. American Academie of Pediatrics. Children and COVID-19: State-Level Data Report https:// Accessed on September 19 th 2021.

43. Savage R, Chu A, Rosella LC, Crowcroft NS, Varia M, Policarpio ME, et al. Perceived usefulness of syndromic surveillance in Ontario during the H1N1 pandemic. Journal of Public Health. 2012;34(2):195-202.

44. Egger JR, Hoen AG, Brownstein JS, Buckeridge DL, Olson DR, Konty KJ. Usefulness of school absenteeism data for predicting influenza outbreaks, United States. Emerging infectious diseases. 2012;18(8):1375.

45. Besculides M, Heffernan R, Mostashari F, Weiss D. Evaluation of school absenteeism data for early outbreak detection, New York City. BMC public health. 2005;5(1):1-7.

46. Haber NA, Clarke-Deelder E, Salomon JA, Feller A, Stuart, EA. COVID-19 Policy Impact Evaluation: A guide to common design issues, American Journal of Epidemiology, 2021; https://doi.org/10.1093/aje/kwab185

\section{Figures}

\section{Figure 1}

Evolution of the number of reported COVID-19 cases per week per 100,000 children and school-related NPI

Legend: NPI: non-pharmaceutical interventions

\section{Figure 2}

Absolute difference in reported COVID-19 cases per week per 100,000 compared to grade 7-8

\section{Figure 3}

Evolution of the distribution of the percentage of reported COVID-19 cases in school children by grade

Figure 4 


\section{Figure 5}

Evolution number of (positive) SARS-CoV-2 PCR and antigen tests in children 6-18 years old in Flanders

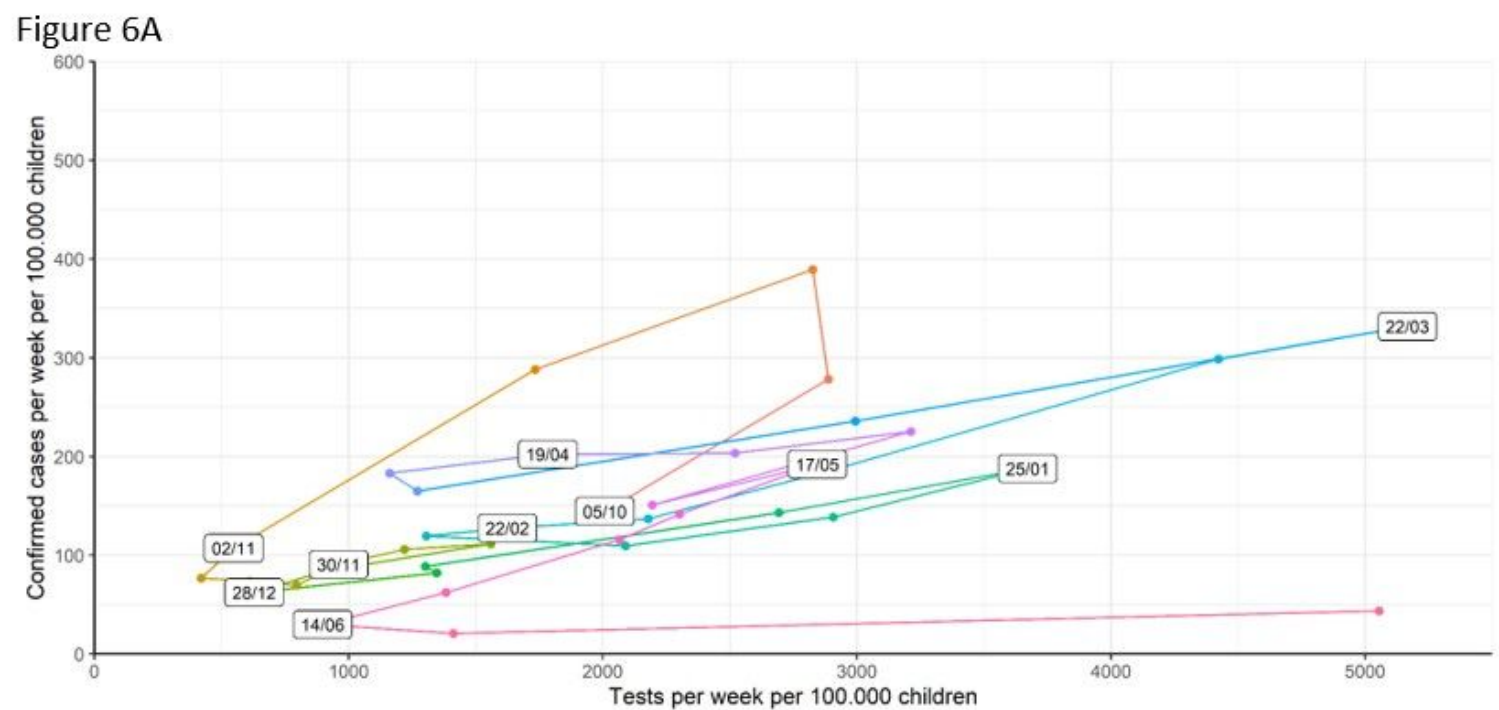

\section{Figure 6B}

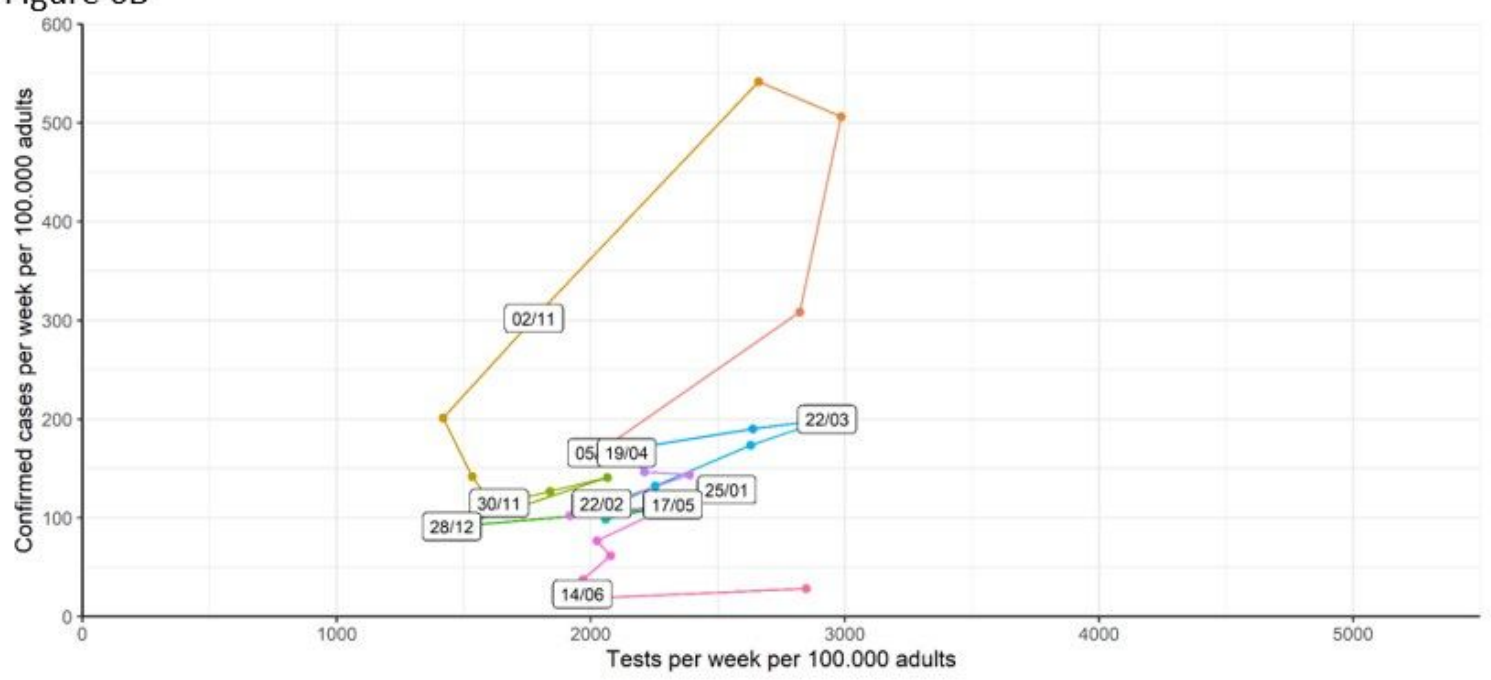

Figure 6

A and B: Number of cases and SARS-COV-2 tests per week in (top) children aged 6-18 and (bottom) people aged 19-80 in the community.

\section{Figure 7}

Reporting effectiveness: Moving window ratio cases captured in the surveillance network/Sciensano test-positive cases in children 6-15 years old

\section{Supplementary Files}

This is a list of supplementary files associated with this preprint. Click to download.

- Supplement20211221.docx 